\title{
Visual Evaluation of Soil Structural and Sugarcane Root Under Deep Strip-till and Conventional Tillage
}

\author{
Camila Cassante de Lima ${ }^{1}$, Isabella Clerici De Maria ${ }^{2}$, Wellingthon da Silva Guimarães Júnnyor ${ }^{2}$, \\ Laura Fernanda Simões da Silva ${ }^{1} \&$ Raffaella Rossetto ${ }^{3}$ \\ ${ }^{1}$ Universidade de São Paulo, Escola Superior de Agricultura "Luiz de Queiroz", Piracicaba, Brazil \\ ${ }^{2}$ Instituto Agronômico, Campinas, Campinas, Brazil \\ ${ }^{3}$ Agência Paulista de Tecnologia dos Agronegócios, APTA Polo Centro Sul, Piracicaba, Brazil \\ Correspondence: Camila Cassante de Lima, Universidade de São Paulo, Escola Superior de Agricultura "Luiz de \\ Queiroz”, Piracicaba, Brazil. Tel: 55-19-992-340-420. E-mail: camila.cassante@usp.br
}

Received: July 18, 2018

doi:10.5539/jas.v10n11p231

\author{
Accepted: August 21, $2018 \quad$ Online Published: October 15, 2018 \\ URL: https://doi.org/10.5539/jas.v10n11p231
}

\begin{abstract}
The Visual Evaluation of Soil Structure (VESS) is a relatively simple methodology used for comparing management systems and for maintaining or recovering the quality of agricultural soils. The objective of this study was to evaluate the structural soil quality in the production of sugarcane using VESS. Three treatments were established: Deep Strip-till (DST), Conventional Tillage (CT) and Uncultivated area (UC). For DST and CT soil samples were taken from two locations: in-row and inter-row. Soil blocks were extracted from mini-trenches and carefully fragmented into aggregates, whose appearance, resistance, and characteristics of the structural units define quality scores. The density of visible roots was quantified by a grid-based counting method. DST at in-row location had improved the structural quality of the soil, providing greater root growth. Scores of visual soil quality in CT showed no difference between in-row and inter-row locations. Preserved from machinery traffic the in-row trail in CT did not result in benefit to soil quality. Variability in the scores among the replicate blocks for DST in-row suggests that the equipment had produced irregular soil tillage. VESS proved to be a good indicator from which it is feasible to evaluate impacts of agricultural machines and tillage implements on soil quality.
\end{abstract}

Keywords: soil quality, tillage implements, VESS

\section{Introduction}

Knowledge and quantification of the impacts on soil quality of land use and management are important for the development of sustainable agricultural systems (Doran, 2002). The soil quality can be assessed both for agro-ecosystems aiming the productivity and for natural ecosystems where major aims are maintenance of environmental quality and biodiversity conservation. Thus, measuring the quality of a soil means assigning a value to the soil that expresses its capacity to fulfill a specific function, which in the context of arable agriculture equates to providing a suitable environment for plant development (Bünemann et al., 2018).

Quantification of the quality of natural and degraded soils can be performed by visual methods, in which the soil is described in terms of the size, shape, and porosity of its individual structural units (aggregates). Additional descriptors that correlate with soil quality can be added (Ball et al., 2007). Omuto (2008) found that visual evaluation is an inexpensive and rapid method for identifying the final stages of physical degradation with an accuracy of $60 \%$.

Direct, in-field evaluation of the structural quality of soils from the temperate regions have been made by several methodologies (Ball \& Douglas, 2003; Roger-Estrade et al., 2004; Ball et al., 2007; Shepherd, 2009; Mueller et al., 2013; Abdollahi, Hansen, Rickson, \& Munkholm, 2015; Leopizzi et al., 2018). However, few studies reporting the evaluation of the quality of from the tropical regions through visual methods have been conducted (Niero et al., 2010; Dechen et al., 2010; Guimarães et al., 2011; Giarola et al., 2013; Moncada et al., 2014; Cherubin et al., 2016).

In the visual evaluation method developed by Ball et al. (2007) for the evaluation of the structural quality of a soil, called Visual Evaluation of Soil Structure-VESS, scores are assigned according to classes defined in a 
chart. The depictions of soil attributes provided in these charts assist the user in identifying characteristics of the sampled layers of a soil that determine its structural quality. The use of the VESS method has grown because of its simplicity, it requires few equipment for its evaluation, reliability and speed with which the results are obtained (Leopizzi et al., 2018)

Incorrect use of agricultural machinery and equipment has been identified as being pointed as cause of the degradation of soil structure (Roque et al., 2010; Soracco et al., 2015) and hence on the root development of crops (Souza et al., 2012). As a result, there has been growing interest in evaluation the quality of soils subjected to different cultivation processes, with a view to defining the technologies most appropriate for specific climate conditions and soils. Effects on the soil properties vary with the type of tillage followed in the management system, and are dependent on the tillage intensity, the traffic of machines, and the type of equipment used (Roque et al., 2010).

The relative ease and speed with which a soil structure evaluation can be performed by visual scoring makes methods like VESS a practical tool for examining how tillage practices affect soil quality (Ball et al., 2007). Thus, the hypotheses of the study are: for crops raised in rows, regardless of the soil tillage method, the soil quality score for samples from within a row, where there is no traffic of agricultural machines, will be better than for inter-row samples. The in-row scores for a soil managed under deep tillage will be better than for the same soil under other systems of tillage. Through their effects on soil structural quality, tillage practices exert an influence on the development of the root system of the crop. This leads to the expectation that soil quality scores will be related to measures of root growth. The objectives of this present study were to compare the structural quality of an Alfisol under deep strip-till and conventional tillage cultivated sugarcane and to search for relationships between soil structural quality and root system development.

\section{Method}

\subsection{Study Area Description of Treatments}

The field study was conducted in Piracicaba, State of São Paulo, Brazil $\left(22^{\circ} 41^{\prime} 04^{\prime \prime}\right.$ S and $47^{\circ} 38^{\prime} 52^{\prime \prime}$ W). The climate is subtropical with dry winters, corresponding to classification Cwa within the Köppen scheme (Peel et al., 2007). The mean annual temperature and rainfall are $24^{\circ} \mathrm{C}$ and $1273 \mathrm{~mm}$, respectively. The local landscape presents an undulating relief. The soil at the study site was classified as an Alfisol (Soil Survey Staff [USDA], 1999) corresponding to a Nitossolo Vermelho eutrófico latossólico within the Brazilian System for Soil Classification (Santos et al., 2013), with an ochric epipedon, and clay texture (Table 1), with 134.0, 250.5, 115.0 and $500.0 \mathrm{~g} \mathrm{~kg}^{-1}$ of coarse sand, fine sand, silt and clay content, respectively, in surfaces horizons (A and A/B). The soil is free draining, and contains no stones or rocks. 
Table 1. Morphological description of the horizons (H) of the studied Alfisol (Piracicaba, SP, Brazil)

\begin{tabular}{|c|c|c|c|c|}
\hline $\mathrm{H}$ & Depth/m & Color & Texture & Description \\
\hline $\mathrm{A}$ & $0.00-0.10$ & $\begin{array}{l}(2.5 Y R 3 / 2) \\
\text { Dusky red }\end{array}$ & clay & $\begin{array}{l}\text { Structure: moderate, small to medium, angular and } \\
\text { subangular blocks. } \\
\text { Rupture resistance: friable. } \\
\text { Plasticity and stickiness: very plastic and sticky. } \\
\text { Boundary: gradual and wavy. }\end{array}$ \\
\hline $\mathrm{AB}$ & $0.10-0.25$ & $\begin{array}{l}(2.5 \text { YR } 2.5 / 4) \\
\text { Dark reddish brown }\end{array}$ & clay & $\begin{array}{l}\text { Structure: moderate, small to medium, angular and } \\
\text { subangular blocks. } \\
\text { Clay films: few and faint. } \\
\text { Rupture resistance: friable. } \\
\text { Plasticity and stickiness: very plastic and sticky. } \\
\text { Boundary: diffuse and wavy. }\end{array}$ \\
\hline B & $0.25-0.60$ & $\begin{array}{l}(10 \mathrm{R} 3 / 6) \\
\text { Dark red }\end{array}$ & heavy clay & $\begin{array}{l}\text { Structure: strong, medium to large, angular and subangular } \\
\text { blocks. } \\
\text { Clay films: common and distinct. } \\
\text { Rupture resistance: very friable. } \\
\text { Plasticity and stickiness: very plastic and sticky. } \\
\text { Boundary: diffuse and wavy. }\end{array}$ \\
\hline $\mathrm{Bw}$ & below 0.60 & $\begin{array}{l}(2.5 \mathrm{YR} 3 / 6) \\
\text { Dark red }\end{array}$ & heavy clay & $\begin{array}{l}\text { Structure: weak, short, angular blocks that fall apart easily } \\
\text { to granular. } \\
\text { Clay films: few and faint. } \\
\text { Rupture resistance: very friable. } \\
\text { Plasticity and stickiness: very plastic and sticky. } \\
\text { Boundary: diffuse and wavy. }\end{array}$ \\
\hline
\end{tabular}

Note. Color $=$ Water state: moist.

The experimental area of 3.50 ha was cultivated with sugarcane under conventional tillage since August 2005 . After two cycles, the area was prepared with conventional tillage for the implementation of the experiment. The experiment was carried out in a completely randomized design (CRD), with 3 plots, each one being a treatment. The plots were demarcated within the experimental area, with dimensions of $120 \mathrm{~m}$ long by $50 \mathrm{~m}$ wide $(0.60 \mathrm{ha})$, one for each treatment. Three replicates were made within each plot. The evaluations were carried out in the cycle of the first ratoon cane.

\subsection{Soil Tillage Treatments}

Treatment 1: Deep Strip-Till (DST) - The deep strip-till of the soil was performed using an equipment that comprises components which simultaneously performed surface tillage, deep tillage with a subsoiler, surface clod breaking, straw windrowing, and the in-row application of lime and fertilizers at different depths $(0.40$ or $0.80 \mathrm{~m})$. The surface soil tillage $(0.00$ to $0.40 \mathrm{~m})$ was carried out with a rotary hoe with 16 blades on each wheel; the deep tillage reached to a depth of $0.80 \mathrm{~m}$, and formed the rows of paired plant beds. Agricultural limestone was applied in-row as part of the deep tillage preparation of the plant beds: $2.00 \mathrm{tha}^{-1}$ of lime (PRNT of $80 \%$ ) at a depth of $0.40 \mathrm{~m}$, and $0.80 \mathrm{tha}^{-1}$ at a depth of $0.80 \mathrm{~m}$.

Treatment 2: Conventional Tillage (CT)-The soil tillage was carried on with a disc harrow (20 discs of $0.61 \mathrm{~m}$ of diameter) for lime incorporation and a leveling harrow to break up clods. These operations extended to a depth between 0.20 and $0.30 \mathrm{~m}$. Thirty-four days after soil tillage (one day before planting), $2 \mathrm{t} \mathrm{ha}^{-1}$ of lime were applied with surface harrowing. The operations on planting day were the application of $0.80 \mathrm{tha}^{-1}$ of agricultural gypsum, incorporated with light harrowing, followed by the formation of the furrows.

Due to a lack of native vegetation near the treatment plots, usually used as a reference in studies on the effects of management systems (Argenton et al., 2005), an Uncultivated area (UC) occupied by bamboo vegetation on the same Alfisol was selected as the reference. There was no history of agricultural operations or traffic of machinery through this area, and the bamboo vegetation had been growing undisturbed for approximately 40 years. 
The sugarcane (variety IACSP95-5000) was planted in a dual row system (Figure 1), with a row spacing of 0.90 $\mathrm{m}$ between the paired rows (in-row spacing), and $1.50 \mathrm{~m}$ between the rows of adjacent pairs (inter-row spacing). The in-row spacing is preserved from machinery, and is known as "seedbed", while the inter-row spacing is the area used exclusively for traffic.

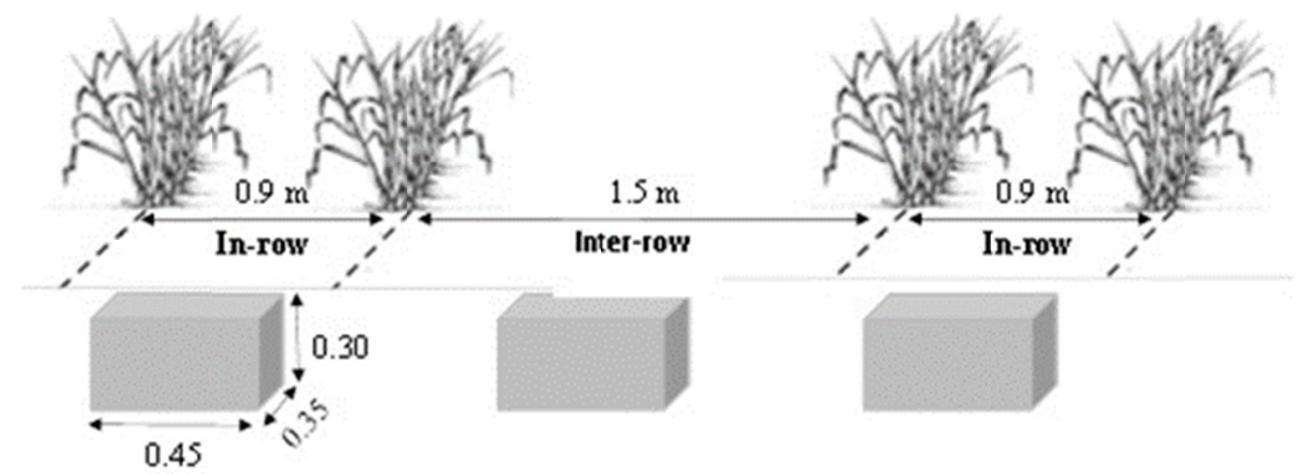

Figure 1. Dual row planting scheme (DST and CT treatments), and locations and dimensions of the mini-trenches from which the soil blocks were extracted

\subsection{Soil Sampling and Visual Evaluation}

The visual evaluation of soil structure was conducted before the harvest of the sugarcane ratoon cycle on samples collected as blocks of surface soil. Soil moisture at the time of extraction of the blocks was $0.20 \mathrm{~kg} \mathrm{~kg}^{-1}$ in layer $0-0.30$, correspondent to the limit of plasticity, which were obtained by gravimetry through the sampling of deformed soil. In DST and CT treatments both in-row and inter-row samples were collected, thereby resulting in five treatments: DST in-row; DST inter-row; CT in-row; CT inter-row; and UC. Three sampling points were positioned in representative locations within each treatment (central position of in-row and inter-row) where three mini-trenches (replicates), for the extraction of soil undisturbed samples, were opened with the aid of a straight spade. The dimensions of the trenches were $0.35 \mathrm{~m}$ wide (parallel to the plant rows) $\times 0.45 \mathrm{~m}$ long (perpendicular to the plant rows) $\times 0.30 \mathrm{~m}$ deep (Figure 1). After extraction, the soil blocks were carefully wrapped and taken to the laboratory where each block was broken into three subsample, top to bottom slices with dimensions of $0.10 \mathrm{~m}$ wide $\times 0.15 \mathrm{~m}$ long $\times 0.25 \mathrm{~m}$ deep, providing nine observations for each of the five treatments.

The visual analysis of the soil structure followed the VESS protocol of Ball et al. (2007). Each soil slice was fragmented manually, respecting the fracture planes between the aggregates. Layers of contrasting structure were identified and measured. For each layer, the evaluation of the structure was based on the appearance (size and color), resistance, and characteristics of the structural units of the fragments (aggregate porosity) and presence/absence of roots and their morphological characteristics. This led to the assignment of an integer score $\left(S q_{i}\right)$ for structural quality to layer $i$ derived by visual classification, with values ranging from $S q_{i}=1$ (best) to $S q_{i}=5$ (worst). The best score is that attributed to the friable soil, in which its aggregates easily break with the fingers and are smaller than $0.006 \mathrm{~m}$ after the break, the soil presents high visible porosity and many roots. Already the worst score is one that the soil presents itself very compact and it is difficult to break. Most of your aggregates are angles greater than $0.01 \mathrm{~m}$. The porosity is very low, may contain anaerobic zones and few rots restricted to cracks (Ball et al., 2007).

The average score $(S q)$ was determined by multiplying the score of each layer by its thickness $(d)$ and dividing the sum by the total depth $\left(\mathrm{d}_{\mathrm{tot}}=\sum \mathrm{d}_{\mathrm{i}}\right)$ (Ball et al., 2007):

$$
S q=\left(\sum d_{i} \times S q_{i}\right) / d_{t o t}
$$

For the analysis of the distribution of sugarcane roots, six trenches were opened in the DST and CT plots (3 in-row and 3 inter-row). The trenches were $3.60 \mathrm{~m}$ long and $1.00 \mathrm{~m}$ deep parallel to the sugar cane plant row. On one side of each trench, the soil profile was leveled in the vertical direction, by removing a thin layer of soil, around $0.03 \mathrm{~m}$, using a rolling scarified. The aim of this operation was to expose the roots, without removing them from the soil. After exposing the roots, a grid with overall dimensions of $2.40 \mathrm{~m}$ long by $1.00 \mathrm{~m}$ deep, covered with a $0.10 \mathrm{~m} \times 0.10 \mathrm{~m}$ square lattice mesh, was fixed to the side of the trench. A visual count of the 
number of roots per unit area in the different layers of the soil was then conducted, without regard to the length, thickness, or branching of the roots.

\subsection{Statistical Analysis}

The soil structural quality scores from the visual evaluation and the root system data obtained from the counting of the roots of sugarcane plants were evaluated through confidence intervals that were computed according to the procedures given by Gabriel (1978).

The median of the replicates values ( 3 replicates $\times 3$ subsamples $=9$ replicates) and only of each replicates $(3$ blocks) was represented in boxes, together with lower and upper limits corresponding to the first and third quartiles, respectively. The ends of the whiskers marked the confidence intervals $(p<0.05)$ for multiple comparisons of the mean values for a variable among the treatments. The Pearson's correlation ( $\rho$ ) between the number of visible roots and the scores obtained for each layer was calculated through software R (R Core Team, 2017).

\section{Results and Discussion}

The visual evaluation revealed small differences in the thickness of the layers 1 and 2, and in the shape and size of the aggregates among treatments (Figure 2).

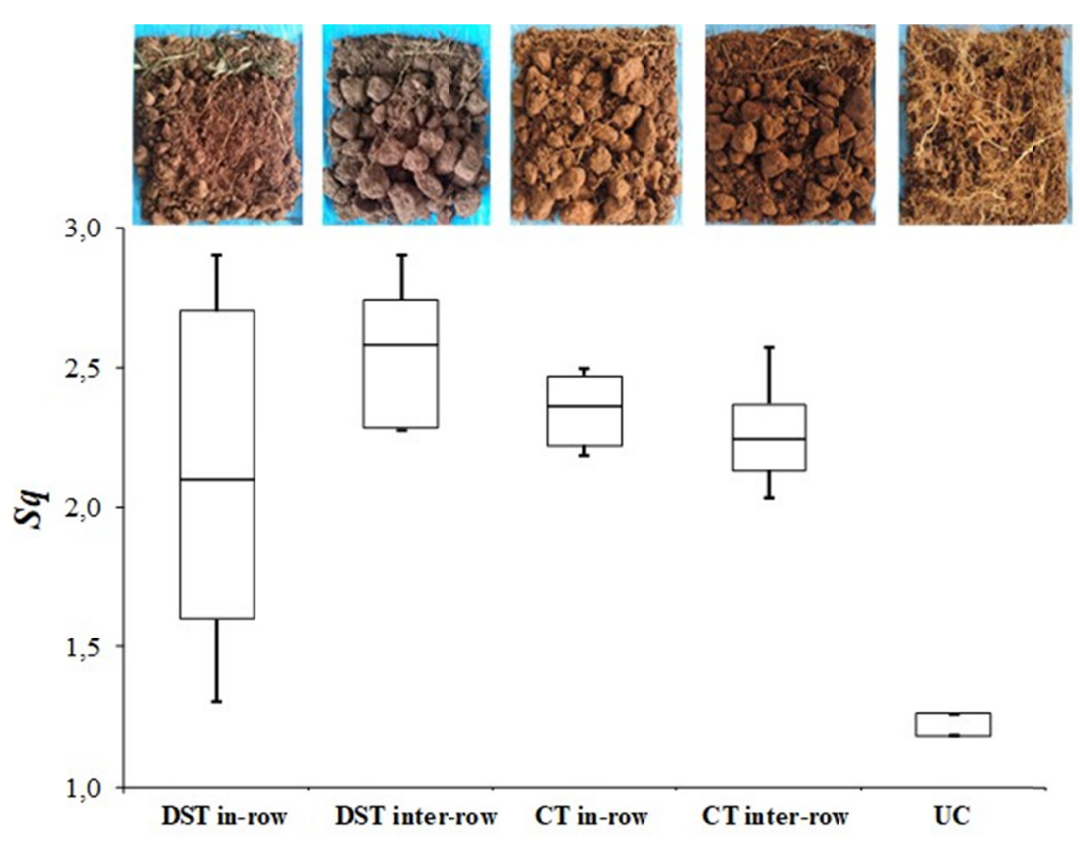

Figure 2. Images after fragmentation of soil samples and overall VESS scores for total soil layer $(0-0.25 \mathrm{~m})$ for the treatments deep strip-till (DST-in-row, DST-inter-row), conventional tillage (CT-in-row, CT inter-row) and the uncultivated area (UC). Whiskers are confidence intervals (Gabriel, 1978, $p<0.05$ ) for multiple comparisons among the treatments

The mean scores $(S q)$ for the structural quality of the soil, obtained from VESS for total layer $(0.25 \mathrm{~m})$ indicate that soil structure changes with treatment, resulting in the following descending order of the median scores: UC $<$ DST, in-row $<$ CT, inter-row $<$ CT, in-row $<$ DST, inter-row (Figure 2). Higher scores indicate deterioration in the quality of the soil structure, but none of the treatments achieved a score of 3.0. According to Ball et al. (2007), scores that do not exceed 3.0 indicate soil of acceptable structural quality, and that the soil conditions provided by the management system are adequate for crop cultivation. Thus, although the cultivated soils displayed soil structure deterioration relative to uncultivated soil, the observed increases in the median scores were not sufficient to be detrimental to the development of the sugarcane crop. Askari et al. (2013) also observed that soil tillage systems did not have detrimental impact on soil structure, although its effects could be discernible by visual analysis. 
Lower scores (median $S q=1.26$ ) were observed in the uncultivated area (UC, Figure 2). The dense root system of the bamboo vegetation, plus the accumulated organic litter on the surface of the Alfisol, probably gave to the UC soil a higher content soil organic matter and a greater biological activity than in the tilled soils. Organic matter and biological activity are factors that increase the binding between mineral particles and consequently produce stable soil aggregates. Soil structural quality scores between 1 and 2 are considered indicators of good soil structure by Ball et al. (2007), were also found by Giarola Tormena et al. (2009); Giarola et al. (2010) and Eurich et al. (2014) for areas of native forest which had never experienced any kind of soil tillage and management.

The DST in-row soil presented the median score $(S q=2.10)$. Excavation of the mini-trenches and the extraction of the blocks were easier for the DST in-row locations than for DST inter-row, CT in-row, and CT inter-row, and this observation was consistent with the higher median score of the DST in-row soil.

DST in-row aggregates revealed a soil of greater porosity, and high friability. The presence of roots between small and rounded aggregates, which could easily be broken with finger pressure, also contributed to the good quality score for the DST in-row soil. The attributes of the aggregates in the DST in-row soil: small, friable, porous, sub-angular and rounded, have been identified by Shepherd (2009) as characteristics of soils with good structure.

However, as shown in the box plot of the median quality scores (Figure 2), the variability of the scores was very high for the DST in-row. This occurred because in the layer 2 of some of the replications soil was composed of porous round aggregates with sizes between 0.002 and $0.007 \mathrm{~m}$ and an abundance of branched roots, mixed with aggregates of $0.001 \mathrm{~m}$ around which the roots observed were flattened and showed horizontal growth.

The median scores for the $\mathrm{CT}$ in-row and $\mathrm{CT}$ inter-row treatments $(S q=2.36$ and 2.24 respectively) were higher than for the DST in-row. Difficulties were found in the extraction of the CT soil blocks from the field, due to the resistance of the soil to the insertion of the blade of the spade, an indication of the presence of a compacted layer. Tormena et al., (2016) also found difficulties in extracting blocks from soil under corn cultivation with mechanized harvesting, where most of them had well-defined horizontal layers, large angular and subangular shaped aggregates, and were difficult to break, which are all signs of soil compaction and poor structure.

CT in-row and CT inter-row presented large subangular aggregates that were resistant to rupture, with a few flattened and grouped roots. These cubic and angular aggregates have higher tensile strength due to their greater density (Guimarães et al., 2011), and are considered a sign of soil compaction. The similar scores of the two CT sampling positions reflected the soil tillage, which used a harrow and a leveler, implements that produced homogenization of the soil, as reported by Tavares et al. (2017) in sugarcane production under conventional tillage. This means that preserved from machinery the in-row trail in this treatment did not result in benefit to visual soil quality.

The highest median score was obtained for the DST inter-row $(S q=2.58)$ mainly because of angular aggregates with sizes ranging from 0.001 to $0.002 \mathrm{~m}$ and little porosity, low quantity of roots, and those present displayed little branching and were flattened. The soil is compacted, not only because agricultural traffic was directed along the inter-row zone, but also because there was no tillage in the soil on the $1.50 \mathrm{~m}$ wide inter-row zone, so that the soil compaction generated in the previous crop cycle was not alleviated.

Two soil layers with structural differences were easily identified regardless of the treatment. The mean depth ranges for the first layer displayed only small variations among treatments (DST in-row $=0.06 \mathrm{~m}$, DST inter-row $=0.08 \mathrm{~m} \mathrm{CT}$ in-row $=0.05 \mathrm{~m}, \mathrm{CT}$ inter-row $=0.07 \mathrm{~m}$ and $\mathrm{UC}=0.05 \mathrm{~m}$ ). The second layer correspond the inferior limited of first layer until $0.25 \mathrm{~m}$ (depth of study).

The structural quality of the soil was always lower for layer 1 than for layer 2 (Figure 3). This differentiation between the two layers was considered due in part to tillage and the traffic of machinery, and partly to the development of the root systems of the sugarcane plants and the incorporation of plant residues on the surface. For the uncultivated soil (UC), the scores of the layers were, as expected, very similar, but also the soil of the deeper layer presented a higher score. Cherubin et al. (2016) studying different land use and management in Brazil, also identified two layers, and the superficial layer $(0.00-0.10 \mathrm{~m})$ always presented better visual quality of the soil structure. As well, Tormena et al. (2016) also noted two layers with visually distinct structural quality in medium texture soil cultivated with corn for 7 years with different management systems. 


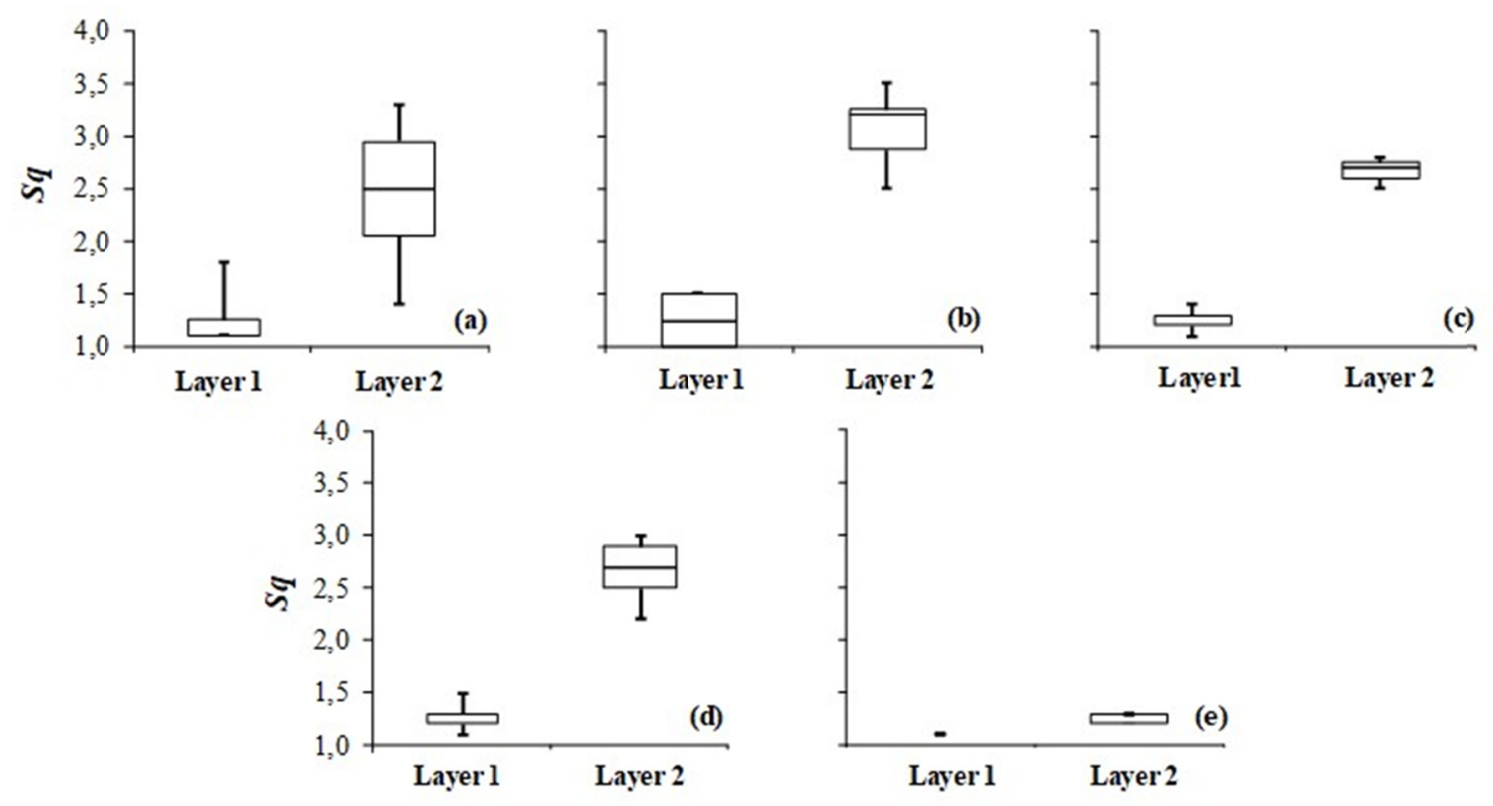

Figure 3. VESS scores of the individual layers for each treatment: (a). DST in-row; (b). DST inter-row; (c). CT in-row; (d). CT inter-row; and (e). UC. Whiskers are confidence intervals (Gabriel, 1978, $p<0.05$ ) for comparisons between the layers

Guimarães et al. (2011) concluded that assigning scores to each individual layer provides more detailed information for future management actions being more appropriate than using a weighted average of the two layers as described by Ball et al. (2007). This applies specially to scores in DST inter-row treatment (Figure 3(b)), with median scores of 1.25 and 3.20, respectively, for the upper and lower layers. In the lower layer, the structural soil quality was classified between firm and compact. The score between 3 and 4 indicates a relatively closed structure with few pores that possess clefts; these soil conditions may restrict the development of the root systems of plants. The aggregates of layer 2 were observed to be angular; the abundance of roots was low, and the roots were seen to be poorly branched and some were flattened. The increase in the median score from layer 1 to layer 2 indicates that better management is needed, especially as the area has a risk for the occurrence of periods of drought during the development phase of the crop.

The variability of scores values in soil blocks for each treatment (DST, CT, or UC) and position relative to the rows (in-row or inter-row) increased with the intensity of tillage (Figure 4). The variability within a block is represented by the difference between the first and third quartile, and among blocks by differences in the median value. In this sense, for soil sampling, Leopizzi et al. (2018) studying soil in growing areas of wheat plants considered homogeneous for purposes of visual analysis of the soil structure concluded that there is $11 \%$ variability between the blocks, being necessary to estimate the average VESS 5 blocks. 

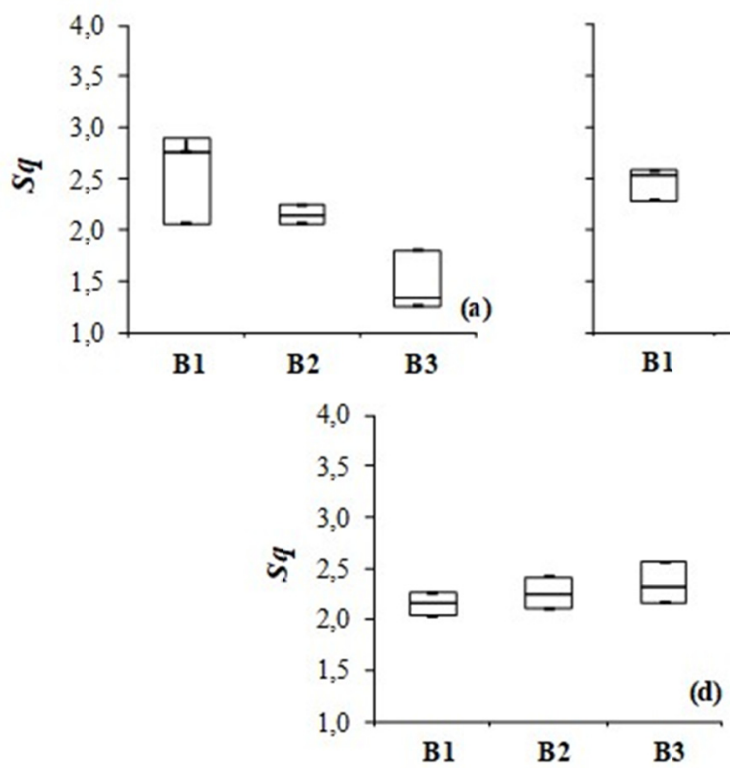

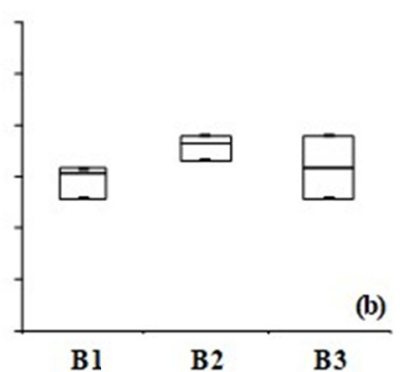

(b)

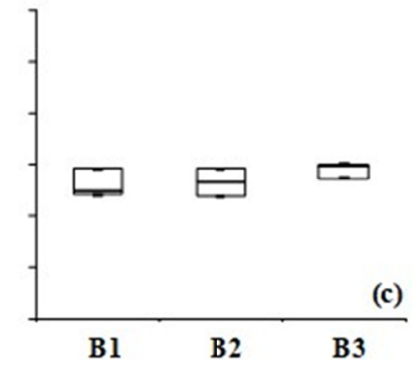

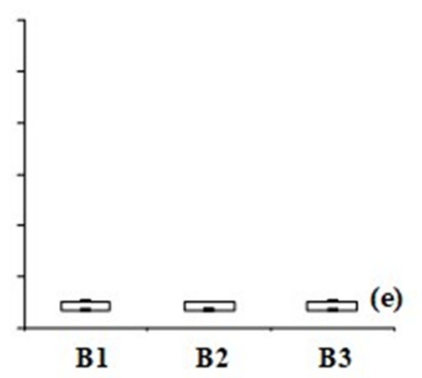

Figure 4. VESS scores of the individual blocks (B1, B2, and B3) from the visual analysis of the soil structure for each treatment: (a). DST in-row; (b). DST, inter-row; (c). CT, in-row; (d). CT, inter-row; and (e). UC. Whiskers are confidence intervals (Gabriel, 1978, $p<0.05$ ) for comparisons among the treatments

The greatest difference among the three extracted blocks (B1, B2, and B3) was observed in DST treatment, and provides an indication of the degree of homogeneity in the preparation of the soil within that treatment. These variations were probably due to the size of the equipment used for the in-row deep tillage of the soil, uneven operation speeds, and small undulations at the surface of the soil. Each of these factors could have modified the forces applied to the in-row soil for fragmentation of clods, which were actively controlled by mechanisms attached to the rotary hoe and the subsoiler. For the inter-row blocks, fluctuations in the pressure on the soil from the wheels of the tractor and implements, imposed by variations in the necessary pulling force, may be invoked to account for the variability.

There were no differences in the VESS scores comparing treatments DST and CT, in-row and inter-row, within layer 1 (Figure 5(a)), with the value for all treatments being equal to 1.2. For layer 2 as well, no statistically significant differences were found (Figure 5(b)).

The counts of the visible roots per unit of vertical area (Figure 5(c) and 5(d)), a measure of the development of the root systems of the sugarcane plants, point to no statistically significant differences among treatments. In layer $1(0.0-0.10 \mathrm{~m})$ it is noted the lower number of visible roots in CT in-row treatment. In layer $2(0.10-0.30 \mathrm{~m})$ higher number of roots visible in the DST in-row stands out.

Pearson's correlation was negative between the number of visible roots and the scores obtained in each treatment for layer 1 and layer 2 (Figure 5) meaning that the variables vary in the opposite direction, that is, the lower the score obtained the higher the number of roots counted. In this way, better soil physical quality under management with traffic control improves root development in sugarcane, as reported by Souza et al. (2012). However, only for DST in-row and CT in-row in the layer 2 the correlation was strong $(\rho=-0.87$ and -0.94 , respectively). In layer 1 the correlation was weak because this layer presented similar structure in all treatments, resulting in close scores. In layer 2, in-row was the position where a higher number of visible roots and a lower score were expected. Pearson's correlation confirms that changes in soil structure in this position are important to infer the root growth. But, also, that in CT treatment soil structure conditions restricted the development of the sugarcane roots. 

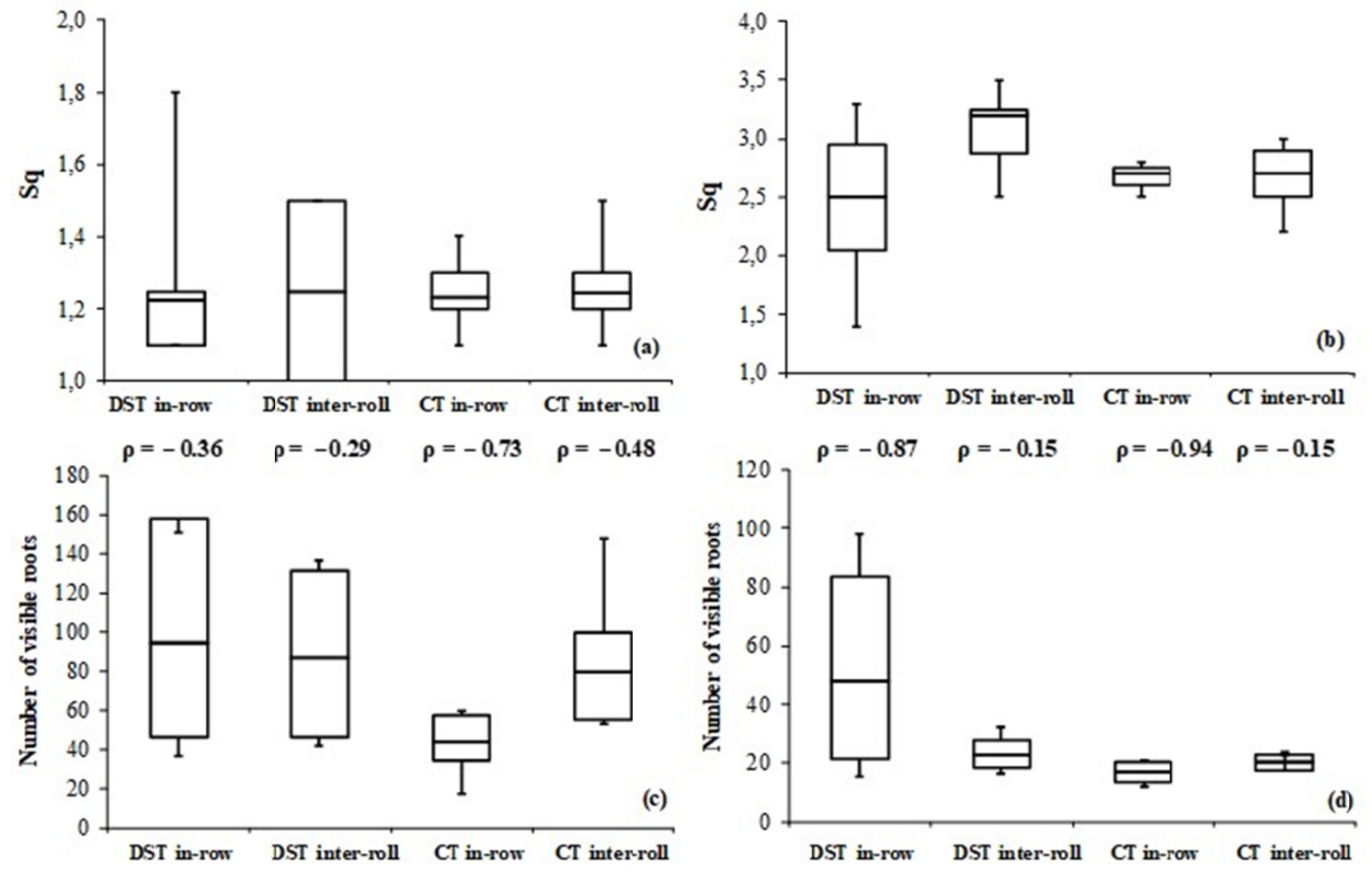

Figure 5. VESS scores of the tillage treatments from the visual analysis of the soil structure for: (a). layer 1; (b). layer 2, and numbers of visible roots per unit area (vertical section) for: (c). layer $1(0.00-0.10 \mathrm{~m})$; (d). layer 2

$(0.10-0.30 \mathrm{~m})$. Whiskers are confidence intervals (Gabriel, 1978, $p<0.05)$ for comparisons among the treatments. Value of $\rho$ between boxplots of each treatment is the Pearson's correlation between the score and number of visible roots

While there were differences in the number of visible sugarcane roots between the different treatments, positions, and layers, attempts to relate these to the soil quality score obtained by visual analysis met with only limited success.

\section{Conclusion}

VESS scores provide an efficient method to assess soil structure quality directly in the field allowing to evaluate tillage implements and soil management practices.

Deep Strip-till presented a lower median mean score for the structural quality in the in-row position in layer 0.06-0.25 m, compared to conventional tillage.

The variations in the soil quality scores among the replicate blocks on Deep Strip-till in-row position indicated that the soil modifications achieved were not uniform along the plant beds prepared with this equipment.

Preserved from machinery, the in-row trail in Conventional tillage did not result in benefit to visual soil quality.

\section{Acknowledgements}

To Grant \#2014/07434-9, São Paulo Research Foundation (FAPESP) and Coordination for the Improvement of Higher Education Personnel (CAPES) for a doctoral scholarship of the third author, and FAPESP for the financial support for the development of this study (Grant \#2013/10427-1).

\section{References}

Abdollahi, L., Hansen, E. M., Rickson, R. J., \& Munkholm, L. J. (2015). Overall assessment of soil quality on humid sandy loams: Effects of location, rotation and tillage. Soil and Tillage Research, 145, 29-36. https://doi.org/10.1016/j.still.2014.08.009

Argenton, J., Albuquerque, J. A., \& Bayer, C. (2005). Comportamento de atributos relacionados com a forma da estrutura de Latossolo Vermelho sob sistemas de preparo e plantas de cobertura. Revista Brasileira de Ciência do Solo, 29(3), 425-435. https://doi.org/10.1590/S0100-06832005000300013 
Askari, M. S., Cui, J., \& Holden, N. M. (2013). The visual evaluation of soil structure under arable management. Soil and Tillage Research, 134, 1-10. https://doi.org/10.1016/j.still.2013.06.004

Ball, B. C., \& Douglas, J. T. (2003). A simple procedure for assessing soil structural, rooting and surface conditions. Soil Use and Management, 19, 50-56. https://doi.org/10.1111/j.1475-2743.2003.tb00279.x

Ball, B. C., Batey, T., \& Munkholm, L. J. (2007). Field assessment of soil structural quality-A development of the Peerlkamp test. Soil Use and Management, 23, 329-337. https://doi.org/10.1111/j.1475-2743.2007. 00102.x

Bünemann, E. K., Bongiorno G., Bai, Z., Creamer, R. E., De Deyn, G., Goede, R., ... Brussaard L. (2018). Soil quality-A critical review. Soil Biology and Biochemistry, 120, 105-125. https://doi.org/10.1016/j.so ilbio.2018.01.030

Cherubin, M. R., Karlen, D. L., Franco, A. L. C., Tormena, C. A., Cerri, C. E. P., Davies, C. A., \& Cerri, C. C. (2016). Soil physical quality response to sugarcane expansion in Brazil, Geoderma, 267, 156-168. https://doi.org/10.1016/j.geoderma.2016.01.004

Doran, J. W. (2002). Soil health and global sustainability: Translating science into practice. Agriculture, Ecosystems \& Environment, 88, 119-127. https://doi.org/10.1016/S0167-8809(01)00246-8

Eurich, J., Weirich Neto, P. H., Rocha, C. H., \& Eurich, Z. R. S. (2014). Avaliação visual da qualidade da estrutura do solo em sistemas de uso das terras. Revista Ceres, 61(6), 1006-1011. https://doi.org/ 10.1590/0034-737X201461060017

Gabriel, K. R. (1978). Simple method of multiple comparisons of means. Journal of the American Statistical Association, 73, 724-729. https://doi.org/10.2307/2286265

Giarola, N. F. B., Silva, A. P., Tormena, C. A., Ball, B., \& Rosa, J. A. (2010). Visual soil structure quality assessment on Oxisols under no-tillage system. Scientia Agricola, 67(4), 479-482. https://doi.org/10.1590/ S0103-90162010000400016

Giarola, N. F. B., Silva, A. P., Tormena, C. A., Guimarães, R. M. L., \& Ball, B. (2013). On the visual evaluation of soil strcture: The brazilian experience in Oxisols under no-tillage. Soil and Tillage Research, 127, 60-64. https://doi.org/10.1016/j.still.2012.03.004

Giarola, N. F. B., Tormena, C. A., Silva, A. P., \& Ball, B. (2009). Método de avaliação visual da qualidade da estrutura aplicado a Latossolo Vermelho Distroférrico sob diferentes sistemas de uso e manejo. Ciência Rural, 39(8), 2531-2534. https://doi.org/10.1590/S0103-84782009000800041

Guimarães, R. M. L., Ball, B. C., \& Tormena, C. A. (2011). Improvements in the visual evaluation of soil structure. Soil Use and Management, 27, 395-403. https://doi.org/10.1111/j.1475-2743.2011.00354.X

Leopizzi, S., Gondret, K., \& Boivin, P. (2018). Spatial variability and sampling requirements of the visual evaluation of soil structure in cropped fields. Geoderma, 314, 58-62. https://doi.org/10.1016/j.ge oderma.2017.11.003

Moncada, M. P., Gabriels, D., Lobo, D., Rey, J. C., \& Cornelis, W. M. (2014). Visual field assessment of soil structural quality in tropical soils. Soil and Tillage Research, 139, 8-18. https://doi.org/10.10 16/j.still.2014.01.002

Mueller, L., Shepherd, G., Schindler, U., Ball, C. B., Munkholm, L. J., Hennings, V., ... Hu, C. (2013). Evaluation of soil structure in the framework of an overall soil quality rating. Soil and Tillage Research, 127, 74-84. https://doi.org/10.1016/j.still.2012.03.002

Niero, L. A. C., Dechen, S. C. F., Coelho, R. M., \& De Maria, I. C. (2010). Avaliações visuais como índice de qualidade do solo e sua validação por análises físicas e químicas em um Latossolo Vermelho distroférrico com usos e manejos distintos. Revista Brasileira de Ciência do Solo, 34, 1271-1282. https://doi.org/ 10.1590/S0100-06832010000400025

Omuto, C. T. (2008). Assessment of soil physical degradation in Eastern Kenya by use of a sequential soil testing protocol. Agriculture, Ecosystems and Environment, 128(4), 199-211. https://doi.org/10.101 6/j.agee.2008.06.006

Peel, M. C., Finlayson, B. L., \& Mcmahon, T. A. (2007). Updated world map of the Köppen-Geiger climate classification. Hydrology and Earth System Sciences, 11, 1633-1644. https://doi.org/10.5194/hess-11-163 3-2007 
Rcore Team. (2017). A language and environment for statistical computing.. $R$ Foundation for Statistical Computing, Vienna, Austria.

Roger-Estrade, J., Richard, G., Caneill, J., Boizard, H., Coquet, Y., Defossez, P., \& Manichon, H. (2004). Morphological characterization of soil structure in tilled fields: from a diagnosis method to the modelling of structural changes over time. Soil and Tillage Research, 79, 33-49. https://doi.org/10.1016/j.still.2004. 03.009

Roque, A. A. O., Souza, Z. M., Barbosa, R. S., \& Souza, G. S. (2010) Controle de tráfego agrícola e atributos físicos do solo em área cultivada com cana-de-açúcar. Pesquisa Agropecuária Brasileira, 45(7), 44-750. https://doi.org/10.1590/S0100-204X2010000700016

Santos, H. G., Jacomine, P. K. T., Anjos, L. H. C., Oliveira, V. A., Lumbreras, J. F., Coelho, M. R., Almeida, J. A., ... Oliveira, J. B. (2013). Sistema Brasileiro de Classificação de Solos (3rd ed.). Brasília: Embrapa.

Shepherd, T. G. (2009). Visual soil assessment: Field guide for cropping and pastoral grazing on flat to rolling country (2nd ed.). Palmerston North, New Zealand.

Soil Survey Staff. Soil Taxonomy [USDA]. (1999). A basic system of soil classification for making and interpreting soil survey ( 2 nd ed.). Washington: USDA.

Soracco, C. G., Lozano, L. A., Villarreal, R., Palancar, T. C., Collazo, D. J., Sarli, G. O., \& Filgueira, R. R. (2015). Effects of compaction due to machinery traffic on soil pore configuration. Revista Brasileira de Ciência do Solo, 39(2), 408-415. https://doi.org/10.1590/01000683rbcs20140359

Souza, G. S., Souza, Z. M., Silva, R. B., Araújo, F. S., \& Barbosa, R. S. (2012). Compressibilidade do solo e sistema radicular da cana-de-açúcar em manejo com e sem controle de tráfego. Pesquisa Agropecuária Brasileira, 47(4), 603-612. https://doi.org/10.1590/S0100-204X2012000400017

Tavares, U. E., Rolim, M. M., Simões Neto, D. E., Pedrosa, E. M. R., Magalhães, A. G., \& Silva, E. F. F. (2017). Aggregate stability and penetration resistance after mobilization of a dystrocohesive Ultisol. Revista Brasileira de Engenharia Agrícola e Ambiental, 21(11), 752-757. https://doi.org/10.1590/1807-1929/ agriambi.v21n11p752-757

Tormena, C. A., Logsdon, D. L. K. S., \& Cherubin, M. R. (2016). Visual soil structure effects of tillage and corn stover harvest in Iowa. Soil Science Society of America Journal, 80, 720-726. https://doi.org/10.2136/ sssaj2015.12.0425

\section{Copyrights}

Copyright for this article is retained by the author(s), with first publication rights granted to the journal.

This is an open-access article distributed under the terms and conditions of the Creative Commons Attribution license (http://creativecommons.org/licenses/by/4.0/). 